\title{
Transitioning to Platform-based Services and Business Models in a B2B Environment
}

By Martin Matzner*, Tobias Pauli, Emanuel Marx, Jürgen Anke, Jens Poeppelbuss, Erwin Fielt, Shirley Gregor, Ruonan Sun, Katja Maria Hydle, Tor Helge Aas, Margunn Aanestad, Jaap Gordijn, Fadime Kaya, and Roel Wieringa

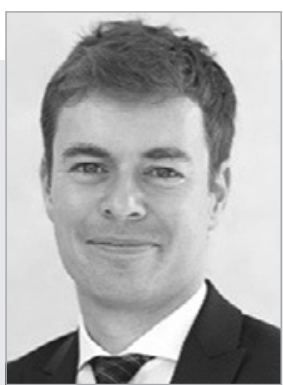

Martin Matzner is Professor of Information Systems and Chair of Digital Industrial Service Systems at Friedrich-Alexander-Universität Erlangen-

Nürnberg, Fürther Straße 248, 90429, Nuremberg, Germany, E-Mail:martin.matzner@fau.de * Corresponding Author.

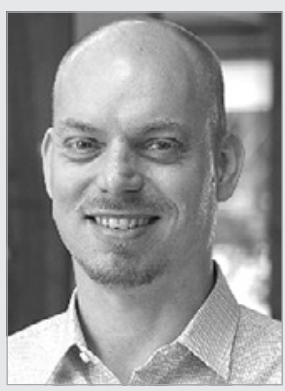

Erwin Fielt is senior lecturer at the School of Information Systems at the Queensland University of Technology, 2 George St, Brisbane,

Queensland, Australia,

E-Mail: e.fielt@qut.edu.au

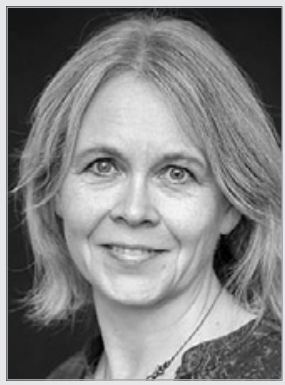

Margunn Aanestad is Professor at the Department of Information Systems, University of Agder, Universitetsveien 25, N-4630 Kristiansand, Norway, E-Mail: margunn.aanestad@uia.no

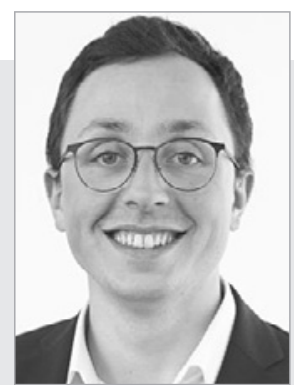

Tobias Pauli is researcher at the Chair of Digital Industrial Service Systems at Friedrich-Alexander-Universität Erlangen-Nürnberg,

Fürther Straße 248, 90429, Nuremberg, Germany, E-Mail: tobias.pauli@fau.de

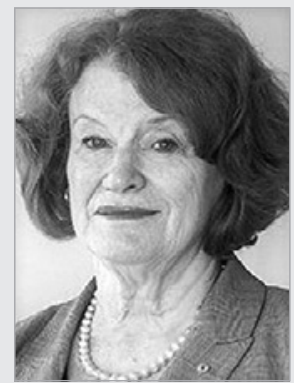

Shirley Gregor is a Professor Emerita at the Australian National University, CBE Building 26C, Kingsley St., Canberra, ACT 2600 Australia and a Schöller Senior Fellow of the Friedrich-Alexander University Erlangen-Nuremberg. E-Mail: Shirley.Gregor@anu.edu.au

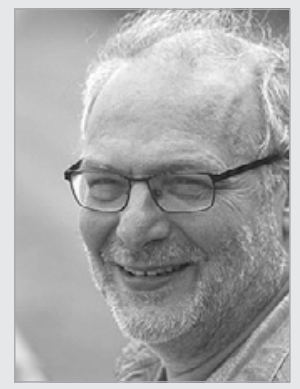

Jaap Gordijn is Associate Professor of eBusiness at the Vrije Universiteit, Ams terdam, Computer Science department, De Boelelaan 1111, 1081 HV Amsterdam The Netherlands, and managing partner of The Value Engineers, The Netherlands, E-Mail: j.gordijn@vu.nl

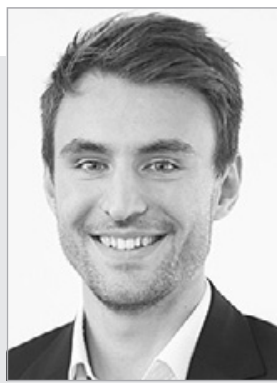

Emanuel Marx is researche at the Chair of Digital Industrial Service Systems at Friedrich-Alexander-Universität Erlangen-Nürnberg, Fürther Straße 248, 90429 , Nuremberg, Germany, E-Mail: emanuel.marx@ faude

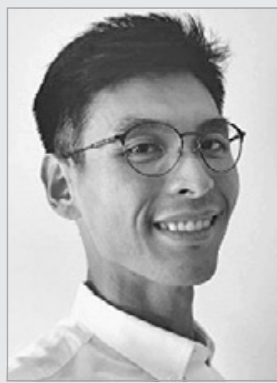

Ruonan Sun is lecturer of management information systems at Lancaster University Management School, Bailrigg, Lancaster, LA1 4YX UK,E-Mail:r.sun5@ lancaster.ac.uk

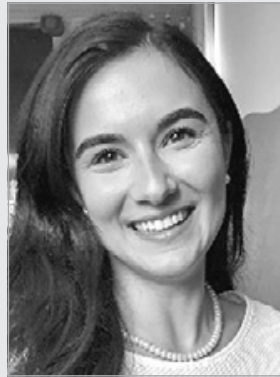

Fadime Kaya is $\mathrm{PhD}$ candidate of Decentralized Governance for Ecosystems at the Vrije Universiteit, Amsterdam, Computer Science department, De Boelelaan 1111, 1081 HV Amsterdam, The Netherlands, E-Mail: f.kaya@vu.nl

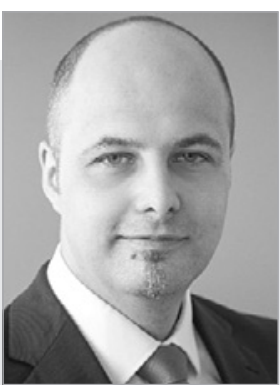

Jürgen Anke is Professor of Software Engineering and Information Systems at Dresden University of Applied Sciences, FriedrichList-Platz 1, 01069 Dresden, Germany. E-Mail: juergen. anke@htw-dresden.de

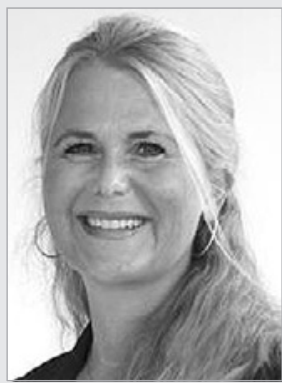

Katja Maria Hydle is Associate Professor at the Department of Informatics, University of Oslo, Gaustadalléen 23 B, N-0373 Oslo, Norway, E-Mail: katjahy@ uio.no

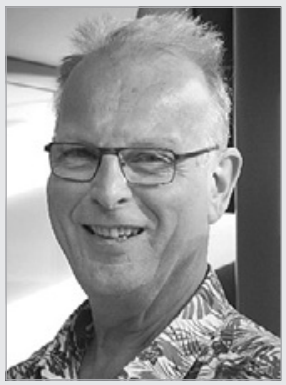

Roel Wieringa is Professo Emeritus of Information Sys tems at the University of Twen te, department of Services and Cybersecurity, Drienerlolaan 5 7522 NB Enschede, The Netherlands and managing partner of The Value Engineers, The Netherlands, E-Mail: roel@ thevalueengineers.nl

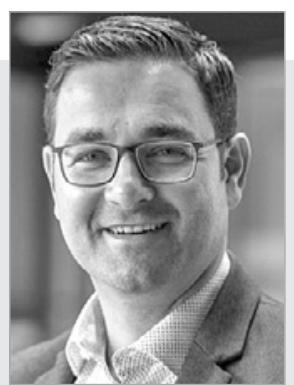

Jens Poeppelbuss is Professor of Industrial Sales and Service Engineering at Ruhr-Universität Bochum, Universitätsstraße 150,

44801 Bochum, Germany, E-Mail: jens.poeppelbuss@ rub.de

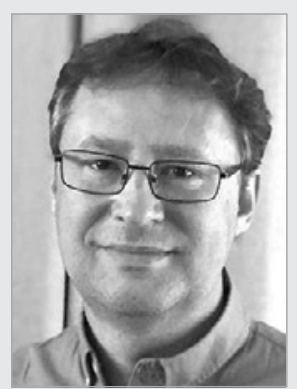

Tor Helge Aas is Professor at the Department of Management, University of $\mathrm{Ag}$ der, Universitetsveien 25, N-4630 Kristiansand, Norway, E-Mail: tor.h.aas@ uia.no 
Given the considerable success of companies such as Apple, Amazon or Airbnb, the term platform is on everyone's lips today. Accordingly, platforms have long since also found their way into service science. However, mastering the transition from established product-sales-based offerings to platform-based services and business models comes with a multitude of challenges. In a B2B context, incumbent companies need to carefully evaluate how they can benefit from the establishment of platforms, especially in light of the effects on their existing business models and ties to other actors. Hence, we invited scholars with different backgrounds to provide viewpoints on the opportunities and challenges of the transition to platform-based services and business models in a B2B environment. The individual commentaries provide various insights on how to conduct this transition and benefit from it successfully. To do so, they contrast different approaches for establishing and governing ecosystems around platforms, discuss B2B-specific pitfalls and opportunities of platform business models, uncover the supporting role of platforms for smart service development, and stress the importance of platform and ecosystem thinking as a necessary mindset.

\section{Introduction}

In recent years, it has become hard to find a company that has not yet considered the development of innovative, platform-based services and business models. In fact, nowadays, platform companies make up a considerable share of the most valuable companies in many branches of the economy. The basis for the success of platform companies is their ability to leverage an ecosystem of actors, allowing for rapid growth through the coordination of external resources and capabilities (Jacobides et al. 2019). However, whereas such a strategy is natural for native platform firms, incumbents may struggle with the transition to platform-based offerings (Hanelt et al. 2020). Against this background, we invited experienced scholars to provide viewpoints on this transition process, including opportunities, potential pitfalls, and strategies to establish platforms and ecosystems successfully.

The authors display diverse backgrounds, coming from the intersection of disciplines such as service science, information systems or computer science, and working on domains ranging from the oil and gas industry to cryptocurrencies. This already serves to show how multifaceted the study of platform-based service and business model innovation can be. By drawing together such a diverse set of perspectives, the special research paper sheds light on many of these facets.
In an overarching commentary, Martin Matzner, Tobias Pauli, and Emanuel Marx discuss the importance of platform and ecosystem thinking, that is, adopting a mindset that acknowledges the peculiarities of value creation and capture in platform-based ecosystems. In view of the tremendous past impact of tools for business model visualization, they stress the role of modelling as a potential catalyst for the adoption of such a new mindset.

Jürgen Anke and Jens Poeppelbuss take a closer look at the role of platforms in smart service innovation by uncovering how they facilitate collaboration across different phases of the innovation process. Their commentary provides an interesting overview of the variety of platforms used by practitioners, from the initial conceptualization and validation of new service ideas to their actual implementation.

Erwin Fielt, Shirley Gregor, and Ruonan Sun present intriguing thoughts on both the vast potentials and the myriad challenges for platform-based business model innovation in a B2B environment. In light of these challenges, they call for mindful decision making that considers existing business models and relationships and embraces platform business model complexity to create unique competitive advantages.

Katja Maria Hydle, Tor Helge Aas and Margunn Aanestad display insights into the digital transformation of the oil and gas industry. Closely following the actions of a native platform firm and an industrial incumbent, they contrast two opposing strategies for digital platform establishment. This allows for valuable lessons learned regarding the different effects on the platform owners' business models and the other actors in the ecosystem.

In the last commentary, Jaap Gordijn, Fadime Kaya, and Roel Wieringa provide a critical viewpoint on the prevailing dominance of centrally governed platform ecosystems, stressing the resulting negative economic and social effects. Subsequently, they call for decentralized governance of ecosystems using blockchain technology. Based on several examples, they show that existing blockchainbased ecosystems already decentralize operation, but typically not governance. Thus, the authors propose an ontology for facilitating comprehensible and transparent onchain governance.

\section{The Move towards Platform and Ecosystem Thinking}

\section{By Martin Matzner, Tobias Pauli, and Emanuel Marx}

"Platform" and "ecosystem" have undoubtedly been among the most frequently used terms for several years in disciplines such as management, information systems, or service science. However, at a closer look, a large body of 
literature reveals that these concepts are more than simply buzzwords but are instead backed by unique properties that provide significant potential for competitive advantages.

It has often been noted that platforms follow peculiar logics for value creation and capture. To a large degree, this can be summarized by the idea of the "inverted firm" (Jacobides et al. 2019; Parker, van Alstyne and Jiang 2016). Indeed, this is what makes platform business models so successful: Instead of purely relying on internal resources and capabilities, they allow firms to leverage an ecosystem of external parties.

Such ecosystems, be it in the form of platform ecosystems or other types such as business or innovation ecosystems, deviate from other collaborative arrangements of actors that established firms typically find themselves in. The central characteristic of ecosystems is a certain degree of absence of hierarchical control (Jacobides et al. 2018). Instead, coordination is achieved through the pursuit of an envisioned collective benefit (Powell 1990).

As established businesses move towards platform-based smart services and business models, they need a new mindset to master this transformation. Such a mindset is often described as "platform thinking" (Leijon et al. 2017). Similarly, there is an increasing awareness of the implications of ecosystems for firms' strategies (Adner 2017), requiring what could be named "ecosystem thinking".

Against this background, this commentary serves three purposes. First, it aims to provide some brief thoughts about what platform and ecosystem thinking respectively may entail in the context of platform-based service and business model innovation. Second, it discusses how a necessity of such change in mindset is reflected in the different commentaries that make up this special research paper. Third, it presents some deliberations regarding the role of modelling in supporting such a necessary change in mindset.

\section{Digital Innovation and Platform Thinking}

Almost a century ago, Schumpeter recognized that innovations are rarely radical, but, in many cases, arise from the recombination of existing resources (Schumpeter 1934). In this process, existing solutions can be split up and transferred to new solutions (dissociation), two or more existing solutions can be combined into novel solutions (association), or new elements can be applied to an existing solution (addition) (Beverungen et al. 2018). Nowadays, innovators enjoy an almost infinite pool of resources that can be used for recombination (Keijl et al. 2016), among other things, due to the advent of digital technologies. Two fundamental properties of digital technologies are responsible for this development (Walter- mann and Hess 2020). On the one hand, they are reprogrammable; they can be adapted flexibly and quickly to new contexts. On the other hand, digital media can be stored, distributed, processed, and displayed on any digital product. This decoupling of physical media from information or content inherent in both these properties is what Lusch and Nambisan (2015) call 'resource liquefication'.

However, the mere existence of (digital) resources is only one aspect of a larger picture of how innovation is enabled. Lusch and Nambisan (2015) continue their reasoning and argue that an efficient and effective distribution of (digital) resources to the right actors is also necessary for innovation. To achieve this, digital platforms are increasingly being deployed in the B2C and B2B sectors. On the one hand, platforms act as a technological basis (Baldwin and Woodard 2008; Wheelwright and Clark 1992) that offers central, standardized components, so-called boundary objects, which can be used to develop applications (Becker et al. 2013; Petrik and Herzwurm 2020). On the other hand, platforms represent an extension of the classic marketplace where supply and demand meet, and different players can trade and interact with each other (Eisenmann et al. 2006; Rochet and Tirole 2003). In most cases, platforms combine both of these types (Schreieck et al. 2016). For example, users of the Siemens MindSphere platform can develop apps for it and distribute them via the integrated app store.

In their fundamental nature, platforms differ significantly from previous products and services and require a transition within the company towards platform thinking as a new mindset. Sawhney (1998: 54) coined the idea of platform thinking as "the process of identifying and exploiting the shared logic and structure in a firm's activities and offerings to achieve leveraged growth and variety". Building on this notion but adding a more external focus, Leijon et al. (2017: 4767) refer to platform thinking as "an approach where incumbents understand their core products as platforms that can be exposed to genuinely new innovation areas for generating complementary products and eventually new revenue streams". Similarly, Trabucchi and Buganza (2021: 19) view platform thinking as "the ability to see Hybrid Multi-Sided Platforms as a useful resource-orchestration structure to unveil innovation opportunities".

These conceptualizations have in common that platform thinking revolves around the idea that platforms mostly gain or create value through complementary products and services. Accordingly, the tangible and intangible components of the platform must be designed in a modular fashion that facilitates several combinations (Schilling 2000; Yoo et al. 2010). Along with the technical design of the interfaces, the focus here is on maintaining a balance between standardization (to enable economics of scale, ease 
and accelerate development, and maintain quality and safety) and heterogeneity (to reach more innovativeness and allow for improved customization on customer needs) (Hofman and Meijerink 2015). Furthermore, platform thinking includes the awareness of the importance and willingness to open the platform, i.e., to give external actors efficient and convenient access to the platform and its individual components (Hurtta, Kim and Elie-Dit-Cosaque 2017) and develop appropriate governance structures (Helfat and Raubitschek 2018). While researchers on digital platforms regularly refer to the platforms' enabling role on innovation outcome (i.e., facilitating new products, services, and business models), platforms can also be utilized in the innovation process itself. In their commentary, Anke and Poeppelbuss well illustrate this extended focus of platform thinking and demonstrate the varying use of platforms to foster collaboration throughout typical development phases, with a focus on smart service development.

\section{Business Model Innovation and Ecosystem Thinking}

Technological innovations, in many cases, do not occur by themselves but often trigger business model innovation (Baden-Fuller and Haefliger 2013; Rayna and Striukova 2014; Tongur and Engwall 2014). Digital innovations in general often entail the potential or even necessity for firms to collaborate with other actors because technological innovations are frequently dependent on other innovations and changes in the concerned ecosystem to be successful (Adner 2006; Adner and Kapoor 2010; Porter and Heppelmann 2014; Yoo et al. 2012). This presents a challenge to many firms because it creates a scenario in which they, in addition to conceiving the multitude of possible business model innovations based on their technological innovations, need to consider increasingly complex ecosystem structures (Turber and Smiela 2014).

This is especially true for digital platforms as novel technologies that offer a foundation for innovation and exchange to an ecosystem of third-party actors (de Reuver et al. 2018; Gawer and Cusumano 2014). Hence, an effect of platform-based business model innovation is the increasing need to cooperate with other firms and thus increasing importance of ecosystems (Westerlund et al. 2014). "Ecosystem thinking" in the context of platform-based business model innovation thus entails an adequate reflection of this new reality in the design and analysis of business models.

According to Osterwalder and Pigneur (2010: 14) "a business model describes the rationale of how an organization creates, delivers, and captures value". Following Zott and Amit (2010: 216), a business model can be regarded as "a system of interdependent activities that transcends the focal firm and spans its boundaries". At its core, the business model concept stresses "value creation through [...] a more complex, interconnected set of exchange relationships and activities among multiple players" (Zott et al. 2011: 1031) than linear supply chains from suppliers to customers. However, although sometimes considered, this boundary-transcending view has for a long time not considerably been reflected in research on business models (Mason and Spring 2011) or the developed tools for business model design and analysis (Weiller and Neely 2013). Nevertheless, this commentary is by no means the first to point out the growing shortcomings of a purely firm-centric business model perspective. On the contrary, since Mason and Spring's (2011) criticism of the dominance of a firm-level application of the concept, there have been many endeavours of researchers to draw attention to an 'ecosystemic' view on business models, only some of which can be discussed here.

For example, Bankvall et al. (2017) conceptualize what they call a "network-embedded" business model as opposed to a firm-centric perspective, describing it as encompassing "a set or network of firms involved in business exchanges that can only be understood and described at the network level" (Bankvall et al. 2017: 199). Westerlund et al. (2014) stress the embeddedness of business models in larger business ecosystems and consequently argue for considering the resulting interdependencies. In a similar vein, $\mathrm{Pa}-$ lo and Tähtinen (2013) call for a consideration of the interplay between firm- and ecosystem-level business models, especially with regard to service and business model innovation. They stress that such a consideration is especially important in the context of novel technology-based services.

Two different perspectives on ecosystem thinking in the context of business model innovation can be derived from these articles. First, companies need to understand their individual business models as interlinked with the business models of other firms in their ecosystem. As stressed in the commentary by Fielt, Gregor, and Sun, to design complex platform-based business models that are difficult to imitate, companies need to ensure fit between the activities of their business models. Based on Zott and Amit's (2010) conceptualization of business models as activity systems that go beyond firm boundaries as well as Adner's (2017) ecosystem-as-structure perspective, ecosystems may be regarded as systems of business models, which are connected through the activities required to create a certain value proposition. Subsequently, ecosystem thinking entails a consideration of interdependencies of business model elements that go beyond firm boundaries and include other actors' business models.

Second, especially when it comes to digital platforms, there is always an ecosystem-wide business model that 
transcends the business models of the individual actors and serves both as a rationale and a guideline for cooperation and competition. In their commentary, Fielt et al. address the challenge of balancing an existing business model with a potentially new platform business model. Going a step further, we argue that it is necessary to also align one's business model with the overall business model driving the ecosystem. Naturally, such a balancing act comes with numerous tensions that need to be considered and resolved (Mini and Widjaja 2019). This is also reflected in the commentary by Hydle, Aas, and Aanestad, in which they stress the need for peripheral actors in platform ecosystems to assess the overall platform business model's effect on their own business models.

\section{Supporting the new Mindset}

The analysis and design of business models has always benefitted from tools and methods for modelling and visualization (John et al. 2017; Täuscher and Abdelkafi 2017). For example, the Business Model Canvas (Osterwalder and Pigneur 2010), as probably the most widelyknown tool for business model visualization, has been responsible for the increasing adoption of the business model concept in practice. As models help to abstract from reality and thus facilitate understanding and communication, they can play a major role in supporting platform and ecosystem thinking (Arreola González et al. 2019).

Interestingly, even though the landscape of modelling approaches has been criticized due to a lacking ecosystem perspective (Weiller and Neely 2013), there are instances of early approaches adopting such a perspective. The most prominent example for this is probably the $\mathrm{e}^{3}$-value modelling approach, which is "designed to help define how economic value is created and exchanged within a network of actors" (Gordijn and Akkermans 2001: 11). Recently, there have been many more advances in moving business model visualization more towards the realm of platforms and ecosystems (Arreola González et al. 2019).

For example, the Ecosystem Pie Model proposed by Talmar et al. (2020) focuses on the contributions and benefits of actors in innovation ecosystems. Similarly, the Business Ecosystem Management Canvas by Humbeck et al. (2020) attempts to support the design and orchestration of business ecosystems by offering a visual template in reference to the Business Model Canvas. Pauli et al. (2020) designed the Platform Ecosystem Modelling Language to model static properties of platform ecosystems, albeit without adopting a business model perspective. In contrast, the platform ecosystem modelling approach proposed by Vorbohle and Gottschalk (2021) adopts a more dynamic and business-model-driven perspective. Especially in service science, there have been other approaches focusing on (platform-based) smart service systems, such as the smart service system engineering language by Huber et al. (2019) and PS 3 by Lüttenberg (2020).

All these approaches acknowledge the importance of deliberately shaping the external contributions to value creation. However, the landscape of these approaches also mirrors the conceptual ambiguity that characterizes both platform and ecosystem research (de Reuver et al. 2018). Many approaches may refer to the same phenomenon of interest but use different terms. Some approaches focus on platforms as the nucleus of the ecosystem, whereas others choose a certain value proposition as the focal point. Part of the tools employ a rather static perspective, while others stress the importance of considering dynamic interactions. Finally, some approaches focus on single business models within an ecosystem, whereas others aim to describe an overall ecosystem business model.

Knowledge in upcoming research areas typically tends to be somewhat fragmented. This tendency is also noticeable with regard to platform and ecosystem modelling. The large number of approaches that have been developed in recent years shows promising results. In a next step, researchers need to take a step back and attempt to integrate the created knowledge and establish links between the different concepts and levels. Such an integration may provide fruitful ways forward for facilitating an understanding of platforms and ecosystems. As Gordijn, Kaya, and Wieringa propose in their commentary, for example, new modelling techniques developed for specific ecosystem-related usage scenarios may be combined with existing approaches to ease the transition to the new realities of ecosystems.

\section{Platforms in Collaborative Smart Service Innovation}

\section{By Jürgen Anke and Jens Poeppelbuss}

\section{Collaborative Smart Service Innovation}

Service innovation is of critical importance for B2B firms since new service offerings are a key driver of growth and competitive advantage (Biemans and Griffin 2018). In particular, advances in digital technologies spark service innovation in both services-focused firms and products-focused B2B firms (Barrett et al. 2015; Biemans and Griffin 2018; Lusch and Nambisan 2015). As for the former, logistics and engineering service providers, as well as consulting and facility management firms, continuously improve and extend their service offerings by implementing digital platforms that manage supply chains and process transactions online and with a high degree of automation. As for the latter, service infusion and servitization reflect the relevance of service innovation in manufacturing and primary sectors, too (Dayan and Ndubisi 2020). Manufacturing 
firms turn machines and equipment into so-called smart products with embedded systems, sensors, actuators, and networking capability and utilize them to offer smart service offerings, including condition monitoring, predictive maintenance, remote optimization, and fleet management (Allmendinger and Lombreglia 2005; Beverungen et al. 2019; National Science Foundation 2014). With more status and usage data available, revenue models also change from transactional product and service sales towards more relational and long-term approaches such as subscriptions, pay-per-use, and performance-based contracting (Coreynen et al. 2017; Paiola and Gebauer 2020; Weking et al. 2020).

We refer to the process of using digital technologies to change the resource configurations, structures, and value co-creation processes of service systems as smart service innovation (Anke, Poeppelbuss, et al. 2020). Smart service innovation is a collaborative process as it requires the involvement of multiple internal and external actors. These actors take on various roles during the innovation process to end up with novel smart service value propositions that resonate in value-in-use for beneficiaries (Anke, Poeppelbuss, et al. 2020; Ekman et al. 2016; Lusch and Nambisan 2015; Schymanietz and Jonas 2020). Recent studies have begun to investigate collaborative smart service innovation more intensively, taking a service ecosystem perspective that goes beyond the single focal organization or the dyadic perspective of providers and consumers (Anke, Poeppelbuss, et al. 2020; Ekman et al. 2016; Ostrom et al. 2015; Schymanietz and Jonas 2020). With a service ecosystem perspective in mind, it is argued that innovation outcomes rather evolve from a network of actors (including the customer but also other actors) than from a single organization alone (Lusch and Nambisan 2015). Considering the key role of digital technologies for smart service systems, the set of actors relevant for innovating is likely to include specialists in systems integration, user experience design, cloud computing, data analytics, and platform business, who are typically not available within a single firm (Anke, Poeppelbuss, et al. 2020; Djellal and Gallouj 2018). With their diverse backgrounds, these multiple actors rely on different methods, tools, and also platforms, which have to be integrated and coordinated during the collaborative smart service innovation process (Anke, Ebel, et al. 2020). In this research commentary, we summarize some of our empirical insights about the utilization of different kinds of platforms during collaborative smart service innovation along with the three service ecosystem states of initiating, realizing, and outcoming (Edvardsson et al. 2018).

\section{Service Ecosystems and Platforms}

Grounded in service-dominant logic (S-D logic), Lusch and Nambisan (2015) define service innovation as the rebund- ling of diverse resources in a way that is beneficial to actors in a specific context. They also emphasize that this almost always involves a network of actors, which can also be understood as service ecosystems. A service ecosystem is defined as "a relatively self-contained, self-adjusting system of mostly loosely coupled social and economic (resource-integrating) actors connected by shared institutional logics and mutual value creation through service exchange" (Lusch and Nambisan 2015: 162). Hence, service innovation is the process that changes institutional logics and value creation processes. Platforms can improve the efficiency and effectiveness of service exchange by facilitating the provision and integration of resources between actors (Lusch and Nambisan 2015). As illustrated above, platforms can be considered the outcome of service innovation processes (e.g., in terms of an energy trading or fourth party logistics platform), but also be an enabler for the coordination of activities and integration of resources during this very innovation process (Nambisan 2013).

Platform is an ambiguous term that can mean different things depending on context. Platforms can consist of both tangible and intangible components and, hence, they can refer to both concrete (e.g., digital interfaces) and abstract entities (e.g., rules of exchange, architecture of participation) (Lusch and Nambisan 2015). Platforms can also be approached from different perspectives (Beverungen et al. 2020; Hein et al. 2020; Poniatowski et al. 2021), including, e.g., a market-based perspective, technical perspective, or a socio-technical perspective (Hein et al. 2020). An economic platform can be a multi-sided market that brings together demand and supply of resources. A technical platform is an infrastructure for the development, test, and operation of software systems, which increases efficiency through standardized services (Hevner and Malgonde 2019). Examples include cloud computing infrastructures, Internet of Things (IoT) platforms, and systems for distributed version control, e.g., GitHub. These platforms do not only simplify technical development through reusable building blocks but also support collaboration through a common environment. Finally, adopting a social-technical perspective, platforms "integrate and govern an ecosystem of actors" (Hein et al. 2020: 89). This includes the facilitation of communication, collaboration, and coordination of multiple actors, which we typically find in smart service innovation. Examples include issue tracking systems like Jira, collaborative document editing systems like Confluence. Moreover, open innovation platforms (Adamczyk et al. 2011) that employ crowdsourcing approaches can source ideas from employees, gather insights into customer needs, collect feedback on prototypes, or facilitate largescale community-driven innovation. Examples include BrightIdea $^{1}$ and HYPE Innovation ${ }^{2}$.

\footnotetext{
https://www.brightidea.com/

https://www.hypeinnovation.com/en/
} 
Using platforms during collaborative smart service innovation can lead to the emergence of new roles, that is, roles that provide the platform for collaboration during the innovation process (e.g., Jira, Confluence, or BrightIdea) and those who provide platforms as a part of the innovation outcome (e.g., a cloud computing or IoT platform). Actors assuming such a role have created or acquired resources that allow them to provide platforms to themselves and others, which makes them part of the service ecosystem. Thus, while platforms are generally said to facilitate service exchange (Lusch and Nambisan 2015), using them may also increase the ecosystem's complexity through the introduction of additional actors and roles.

\section{Platforms in Different States of the Innovation Process}

The S-D logic argues for "an ecosystemic and dynamic view of service innovation" (Edvardsson et al. 2018: 87). Reflecting the dynamics of service innovation and the use of platforms in collaborative smart service innovation, we refer to the states of the innovation process as conceptualized by Edvardsson et al. (2018), which include (1) initiating, (2) realizing, and (3) outcoming. In our recent study, we illustrate that these states can be related to both changes in the set of involved actors and/or the roles they assume (Anke, Poeppelbuss, et al. 2020) during smart service innovation. Correspondingly, the interactions and service exchanges to be facilitated by platforms also depend on the type of innovation activities and the participating actors in the respective state of the smart service innovation process.

The initiating state focuses on formulating intended value propositions that are attractive to potential beneficiaries, including customers and other actors (Edvardsson et al. 2018). This initiation of the innovation process is typically driven by a focal firm in the role of the project sponsor and designated future smart service provider, possibly together with partners and/or customers. In this state, innovation activities focus on the identification and evaluation of customer needs as sources for ideas. In line with the concepts of open innovation, platforms can help to gather, rate, and manage service ideas from the knowledge of a potentially unlimited number of customer representatives. In our research, we found the use of so-called prediction markets, which were used to validate early hypotheses and to collect opinions on features and pricing of a smart parking service through thousands of users.

In the realizing state, ideas are elaborated into service concepts, which are then implemented into value-in-use for the engaged actors (Edvardsson et al. 2018). During this state of the innovation process, the actors involved, the resources they provide, and, hence, institutional arrangements change. The participating actors decide on their roles for providing the future value proposition, including revenue models (Edvardsson et al. 2018). Missing resources have to be identified and integrated through additional actors to be able to achieve an operational status after market launch. Often, dedicated projects are set up during the realizing state to consider cost, time, and quality as constraints (Anke, Poeppelbuss, et al. 2020). To adhere to these constraints, contributions are frequently sourced from actors that are external to the focal service provider. Moreover, the character of innovation activities changes from creativity to engineering, often following contemporary approaches of iterative, agile, and user-oriented software development. To facilitate this type of work, our informants consistently mentioned that they use software development platforms, including those for collaborative development (e.g., GitHub), agile project management (e.g., Confluence, Jira), as well as hosting and experimenting with prototypes (e.g., Amazon Web Services, Microsoft Azure). Besides these, we have also found the use of platforms for crowd testing, which enable feedback on user interfaces and prototypes from a large number of potential users. In this state of the innovation process, platforms are not relevant as enablers of collaborative engineering activities but can also be the outcome. For instance, one firm that we interviewed developed an energy trading platform that supports placing tenders in the marketplace, shows current tenders and market pricing (Anke, Poeppelbuss, et al. 2020). The outcome can also build on platforms as an underlying technical or business architecture. One expert in our study reported on a project in which a system integrator built new services for car tracking based on an existing internal data analytics platform (Anke, Poeppelbuss, et al. 2020). Finally, (industrial) IoT platforms are increasingly discussed in practice and research. They are cloud platforms, which can simplify the data exchange, control, and management of smart products in the field (Beverungen et al. 2020; Pauli et al. 2021).

The outcoming state refers to market diffusion and scaling up so that innovative value propositions become sustainable and the service-providing actors can capture enough value to ensure their sustainability (Anke, Poeppelbuss, et al. 2020; Edvardsson et al. 2018). In this state, cloud platforms in their various forms play a major role. Cloud platform providers have usually already been involved in the realizing state as informants and enablers of technical development activities. In contrast, the operations of smart service offerings are more focused on scalability and availability rather than experimentation and prototyping. Some actors might also pursue a platformbased business model, assuming the role of a platform provider (Beverungen et al. 2020). In such a case, platforms do not only act as technical infrastructure for smart service operations but also as economic platforms that facilitate multi-sided markets. In our study, the previously mentioned case of an IT company that turned into a pro- 
vider of an energy trading platform is such an example. It also illustrates the smart service innovation pattern of forward integration very well, which is one of four typical constellations that we found in collaborative smart service innovation (Anke, Poeppelbuss, et al. 2020).

\section{Conclusions}

With this research commentary, we highlighted that smart service innovation takes place in dynamic service ecosystems, in which actors with specialized knowledge are involved. Their interaction can be facilitated by different platforms depending on the state of the innovation process. The distinction of these states can help to better understand the dynamics underlying the network of innovating actors and how they utilize platforms to support resource integration.

Future research on platforms in collaborative smart service innovation should extend the initial empirical insights that we referred to (Anke, Poeppelbuss, et al. 2020) to provide more detailed explanations on the use of platforms by $\mathrm{B} 2 \mathrm{~B}$ firms that engage in service innovation. We think that such explanations are still needed to answer open questions of how and why actors decide on the adoption of specific platforms during innovation processes and what determines the effectiveness and efficiency of platform use. Quite often, it appears that decisions regarding platform adoption are rather driven by actors with a supporting role that develop or provide technical components of a smart service system and who are used to involve multiple stakeholders, including users, customers, and freelancers. At the same time, B2B firms with the focal roles of project sponsors and designated service providers sometimes even still struggle to view innovation as a collaborative process and to find the right institutional arrangements that can unfold strategic advantages for their business. For instance, while becoming a platform provider opens up business opportunities for actors, all actors using this platform trade efficiency gains for a strategic dependency. Given the central role of platforms for efficient service exchange in ecosystems, we see the need for a stronger managerial and strategic approach to organizing smart service innovation, in particular when platforms are not only an enabler of a collaborative innovation process but also a central component of the innovation outcome.

\section{Platforms in a B2B Context: A Business Model Perspective}

\section{By Erwin Fielt, Shirley Gregor, and Ruonan Sun}

\section{Platform Business Models}

Platforms are heralded as superior business models in the digital age. Goodwin (2015) famously said, "Uber, the world's largest taxi company, owns no vehicles. Facebook, the world's most popular media owner, creates no content. Alibaba, the most valuable retailer, has no inventory. And Airbnb, the world's largest accommodation provider, owns no real estate. Something interesting is happening." What all these companies have in common is that they operate a digital platform. Their success has caused a hype in ambitions, with everyone wanting to be the next Uber of $X$ or the Airbnb of Y. However, this situation begs the question of whether these goals are feasible, particularly in a Business-to-Business (B2B) context. A business model perspective may shed light on this issue by highlighting some of the opportunities as well as challenges and suggesting possible paths forward.

Digital platforms are seen as multi-sided marketplaces as well as technological architectures, bringing together ideas from economics and engineering. Gawer (2014: 1245) defines technological platforms as "evolving organizations or meta-organizations that: (1) federate and coordinate constitutive agents who can innovate and compete; (2) create value by generating and harnessing economies of scope in supply or/and in demand; and (3) entail a technological architecture that is modular and composed of a core and a periphery." More specifically, Gawer (2014: 1244) notes that "in order to create value, platforms rely crucially on economies of scope in supply and innovation (for the engineering design view), and economies of scope in demand (for the economics view)." This definition hints at the importance of a business model perspective that looks at the value logic of an organization to see how it creates and captures value (Fielt 2013). While value capture is not stressed by Gawer, this aspect has been a major driver for the popularity of platforms, as noted by Goodwin, who stresses their profitability by being at the interface of supply and demand.

\section{Opportunities for Platform Business Models in the B2B Context}

Let us first address what makes platform business models so popular, in particular their novelty, attractiveness, and versatility. First, while not necessarily new to the world, digital platforms are often new to traditional (B2B) industries and companies and, as such, offer ways to disrupt traditional business. Digital platforms have gained popularity in the tech industries, where new products and services are often based on or supported by new business models, as in the examples provided by Goodwin. Now digital platforms are also gaining traction in B2B markets where the traditional way of working can be described as pipelines that create value by controlling a linear series of activities (van Alstyne et al. 2016). Platform business models do not operate through control but through leverage, where an impact is generated that is disproportionately larger than the input required (Thomas et al. 2014). This characteristic makes it very hard for traditional pipeline 
businesses to compete with platform businesses and, as such, drives start-ups, tech companies, and even incumbents to launch new digital platforms to disrupt traditional (B2B) markets.

Second, platforms are seen as very attractive business models. Seven of the ten largest global firms by market capitalization operate platforms: Apple (1), Microsoft (3), Amazon (4), Alphabet (5), Facebook (6), Tencent (7), and Alibaba $(9)^{3}$. One of the reasons platform business models are so attractive is that they have very low-cost structures and very high gross margins once they are scaled up (Hagiu and Rothmann 2016). In addition, platforms often generate significant amounts of data, which can be used to drive revenues and as an economic asset. Platform business models enable their owners to capture a significant part of the value created for their users through positive network effects and winner-takes-all economics. Network effects, also known as demand-side economies of scale (van Alstyne et al. 2016), can be same-side (within a user group) or cross-side (between user groups) (Parker, van Alstyne and Choudary 2016). Positive network effects make the platform more beneficial for its users as it grows exponentially. These effects can also lock in users while creating entry barriers for competitors and, as such, establish a strong competitive position.

Third, platform business models are very versatile. Above, we noted that platform business models create value through leverage, which can be applied in different ways: production leverage, innovation leverage, and transaction leverage (Thomas et al. 2014). The (re)use of a collection of assets and the interfaces and standards can enable sharing to drive economies of both scale and scope (production leverage) and economies of innovation and complementary (innovation leverage). The shaping of market pricing and access can drive transaction efficiency and reduce search costs (transaction leverage). There are different types of platforms possible, for example, platforms with peer-provided assets and platforms with asset control (Mody et al. 2020). Platform business models can also have various degrees of openness. While some platforms are internal, others are external and either private or public. Private platforms are based on existing relationships and often invitation only. In public platforms, anyone can participate, as long as they fulfil certain criteria. Moreover, with digital technologies evolving, we see that opportunities for platforms are ever-increasing. For example, with the Industrial application of the Internet of Things (IIoT), we see new opportunities for digital platforms in manufacturing (Pauli et al. 2021).

\footnotetext{
${ }_{3}^{3}$ https://www.pwc.com/gx/en/services/audit-assurance/publ ications/global-top-100-companies.html (May 2021)
}

\section{Challenges for Platform Business Models in the B2B Context}

Despite the potential advantages that platform business models offer, many B2B platforms initiatives struggle, with some never launching in the first place while others fail to scale up. Below we discuss some challenges that a platform may face in a $\mathrm{B} 2 \mathrm{~B}$ context, relating to: value creation and capture; implementation; incumbents launching and operating platforms; and platform strategy and competition.

First, there are some fundamental problems with value creation and capture through platform business models in the B2B context. With respect to value creation, B2B markets often involve fewer actors on the demand and supply side compared with $\mathrm{B} 2 \mathrm{C}$ (or $\mathrm{C} 2 \mathrm{C}$ ), and there are existing relationships between most actors. As such, there will be reduced opportunity for a platform to create value by connecting large numbers of (unknown) buyers and sellers and establishing positive network effects. For example, a study by Wallbach, Coleman, Elbert, and Benlian (2019) shows how platform diffusion inhibitors slow down or even thwart positive network effects in competitive B2B networks. Moreover, there may easily be negative network effects, for example, with two dominant players in an industry not wanting to use the same platform. In addition, B2B markets are often a 'small-number exchange,' where there are relatively few qualified suppliers and relatively few substantial buyers. This situation means that individual customers are strategically important and require individual and unique treatment making platforms as marketplaces less relevant. With respect to value capture, in the B2B context, there is often a need for specialized solutions instead of generic apps, as often seen in the B2C context (Pauli et al. 2021). As such, a B2B platform will find it hard to function as an app store, which is a common way for digital platforms to generate revenues in the $\mathrm{B} 2 \mathrm{C}$ context.

Second, implementing a platform business model in a B2B context can also be very challenging and often requires an in-depth understanding. Getting a platform business model right in a B2B setting is more demanding as buying and selling processes in $\mathrm{B} 2 \mathrm{~B}$ markets have specific characteristics and are often more complex (e.g., Brennan 2018; van Weele 2005). For example, buying processes can involve detailed technical proposals, extensive negotiation, personal interactions, and long-term relationship building. As such, it will be more difficult for a digital platform to develop and deliver the right value-adding services for buyers and sellers, with many of them also having their own distinctive purchasing and marketing and sales functions. Moreover, taking a successful platform business model from one context to another is not straightforward. For example, eBay failed in China due to insufficiently 
adapting to cultural differences and the specificity of the Chinese market.

Third, while incumbents in a B2B market may have an advantage due to their in-depth knowledge and established relationships, it may be very problematic for them to launch and operate platform business models alongside their existing business. As noted above, the value logic of traditional, linear business models is based on control, while the value logic of platform business models is based on leverage. This difference may create issues for incumbents, who are also providers of products and services themselves when launching and operating a platform business. When launching a platform business, incumbents may, on the one hand, need to operate their new platform business separately from their traditional business to decrease tensions while, on the other hand, integrate them to increase synergies. When operating a platform business, incumbents will need to manage their dual role of, on the one hand, being the platform owner while on the other hand, often being a seller on the platform. More broadly, B2B platform ecosystems are often characterized by coopetition where the different actors cooperate as well as compete with each other at the same time.

Fourth, even if it is possible for incumbents to launch and operate successful platform business models in a B2B market, issues of strategy and competition need to be considered to achieve platform leadership. This will be different from B2C markets, where generally positive network effects and winner-takes-all economics will decide who will become the dominant player. While early mover advantages may help with creating competitive advantages, the many risks associated with introducing new platforms in B2B markets may make this a very costly strategy. Moreover, introducing new features to further develop a platform and differentiate it from competitors may not lead to competitive advantages if these innovations are easily copied.

\section{Ways Forward for Platform Business Models in the B2B Context}

Given the opportunities and challenges of platform business models in the B2B context, we will end with suggesting some potential ways forward with a focus on incumbents.

First, incumbent organizations need to use mindful decision making instead of jumping on the digital platform 'bandwagon.' The decision to pursue a platform business model should be situated in careful consideration of the specifics and facts of the organization and the B2B context (Swanson and Ramiller 2004). "Mindful decision making involves discriminating choices that best fit a firm's unique circumstances, rather than familiar and known behaviours based on what others are doing" (Fiol and O'Connor 2003: 59). For example, organizations may choose to go for new platform business models with asset control as that offers more potential synergies and fewer challenges in relation to their existing pipeline business models compared to platform business models with peer-provided assets (Mody et al. 2020).

Second, incumbent organizations need to manage the evolutionary change of their traditional pipeline business model with the revolutionary change of their new platform business model. This requirement means becoming an ambidextrous organization that is able to host multiple contradictory structures, processes, and cultures within the same firm (Tushman and O'Reilly III 1996). In particular, they need to keep exploiting their traditional pipeline business models through the refinement and extension of existing competencies, technologies, and paradigms in a physical world while also exploring new platform business models through experimentation with new ways of creating and capturing value in a digital world. Experimentation is important for new platform business models as often initial ideas are incomplete and may not fit the particular circumstances. Moreover, 'the devil is often in the details' with specific design choices still needing to be made that may affect the interests of the different parties involved (Fielt et al. 2008).

Third, incumbent organizations need to embrace the complexity of platform business models. This requirement partially follows from being mindful, including a reluctance to simplify meaning. Organizations have to do the hard work of understanding digital platforms and their strategic potential and operational implementation in their specific situation. Beyond this, complex business models can help organizations create a competitive advantage as they create a better fit with the environment and are less easy to imitate. Complex business models help organizations to deal with contradictory demands from the environment by enabling paradoxical strategies (Smith et al. 2010): for example, the incumbent being a platform owner as well as a provider and cooperating as well as competing with other providers. In addition, complex business models also manifest themselves through the interdependencies between design choices across different elements in the business model, making them harder to copy (Zhao et al. 2020).

Fourth, incumbent organizations pursuing platforms in the B2B context may consider a collaborative approach working with other stakeholders: for example, a platform may be operated by a consortium instead of an individual firm. Alternatively, different platforms may consider how they can co-create value by, for example, adopting open standards so that business organizations may have lower investments to participate in and are less prone to lock-in. As such prominent incumbents can use their digital plat- 
forms to create broader digital innovation ecosystems to tackle some of the significant problems within their industry and create shared value.

In sum, we see platform business models providing opportunities through their novelty, attractiveness and versatility as well as posing challenges in a B2B context related to value creation and capture, implementation, incumbents launching and operating platforms, and platform strategy and competition. We call upon incumbents that are considering operating a platform business model to be mindful, master ambidexterity and experimentation, embrace complexity and consider collaboration.

\section{Platform Democracy or Dominion: The Tale of Two Platform Strategies}

By Katja Maria Hydle, Tor Helge Aas, and Margunn Aanestad

\section{Introduction}

Digital platforms have transformed industries by reorganising collaboration patterns among the participants in the platforms' ecosystem (Jacobides et al. 2018; Kohtamäki et al. 2019; Parida et al. 2019). Many B2C platforms exhibit rapid scaling trajectories through quick growth in the customer base (Huang et al. 2017). However, digital platform providers in the $\mathrm{B} 2 \mathrm{~B}$ context tend to follow different growth patterns (Penttinen et al. 2018).

While platforms and their associated ecosystems may be understood as new organisational forms positioned to create and capture value (Gawer 2020), an overlooked topic in the literature is the link between business models and ecosystem dynamics (Autio and Thomas 2020) or, more specifically, the underlying mechanisms of value creation, delivery and capture in platforms and ecosystems (Jacobides et al. 2018), especially in the B2B context.

The business model of an entity, such as an organisation or a platform, is typically understood as a model explaining (1) what the entity offers to customers (the value proposition), referred to as 'value creation'; (2) how the value proposition is delivered to customers (e.g., activities, resources, partnerships, channels), referred to as 'value delivery'; and (3) why the value proposition is delivered to customers (e.g., with regard to revenue streams, cost structure), referred to as 'value capture' (Osterwalder and Pigneur 2010).

Thus, it can be argued that the business model represents the fundamental business logic of an entity that, in turn, is related to the strategic choices the entity makes, including the plan and the corresponding activities that are needed to create a valuable position (Casadesus-Masanell and Ricart 2010). Work related to strategy development and implementation has traditionally been understood as activi- ties happening within the borders of an entity without displaying the choices to external partners (Appleyard and Chesbrough 2017); however, more recent strategy literature acknowledges that external actors can also be involved in strategy development and implementation in open strategy processes in which strategy information is made visible for both internal and external actors (Whittington et al. 2011).

In this commentary, we lean on this understanding to discuss strategies and business models used for B2B digital platforms. We discuss how different B2B platform strategies and related business models are used, as well as the implications for the platform owner, the operational activities of customers and the involved ecosystems. We base this discussion on observations and empirical case material from two digital platforms in the Norwegian oil and gas industry.

\section{Two Opposite Strategies and Business Models of B2B Platforms}

The oil and gas industry is currently undergoing major restructuring and transformation as traditionally high-profit margins are replaced with reduced demand and downsizing (Barbosa et al. 2020). Digital technology in general and digital platforms, in particular, are currently being utilised in this industry as a response to the demanding market situation.

However, the way digital platforms are used to create, deliver, and capture value varies. In an ongoing research project in the oil and gas industry, we have identified two digital platforms pursuing radically different business models and strategies. Both platforms approach customers who own industrial production facilities such as oil and gas companies and offer services for data processing, analysis, and integration of various data types from different data sources. The data integration services include connecting various operational data harvested from sensors integrated into the production equipment (time, process, and activity series data) with related contextual information, such as weather information, downtime on other related equipment, vibration data etc. These data integration services can enable a transition from a traditional calendar-based and reactive maintenance regime to a more cost-efficient proactive and condition-based regime. In addition, the data enable more efficient operations, for example, by improving the basis for accurate planning of drilling and well construction processes, reducing the completion time and cost of these processes.

Although the two digital platforms identified had many commonalities related to the services offered, we observed significant differences regarding their strategies and business models. While one platform pursued an open strategy, hereinafter referred to as the Open Platform Strategy, 
the other platform had a closed strategy, hereinafter referred to as the Closed Platform Strategy. In the following, the two identified strategies and associated business models are described:

The Open Platform Strategy: In this case, the digital platform and its central services were initially developed in collaboration between a digital platform company and its initial customer (an oil company) (for a description, see Hydle et al. 2021). The platform company was a tech startup established in 2016 with limited industrial domain knowledge. The platform company has seen large growth since its initiation and is still accelerating and scaling up its services globally.

Guided by a belief in the value of liberating industrial data, the platform company is aiming to enable digital transformation by making data from different systems accessible for the ecosystem of industrial actors through the platform. Transparency and openness of data are the basic foundations of the platform company's strategy. Open data and the sharing of data between all the actors in the industrial ecosystem, including customers, suppliers of equipment, maintenance providers, software developers and others, are understood as the key to more effective and efficient work processes benefitting all actors. Ecosystem actors are invited to take part in the platform either through the development of their own applications on open APIs or through the use of the platform. Transparency, for instance of performance data of interrelated machinery, is beneficial for all industry actors involved.

Furthermore, the ecosystem's actors are encouraged by the platform firm to share experiences and insights on the use of data in order to learn from each other and to be able to bond together. Such experience sharing is enhanced through seminars facilitated by employees of the platform firm. The business model supporting the strategy may be described as follows:

How the platform creates value: The platform provides access to data from different data sources in a contextualised and aggregated manner. The data management services from the platform assist the maintenance and production processes of industrial asset owners by enabling smart maintenance, digitally-enabled operations and smooth collaboration, and subsequently increased cost-efficiency. By using the platform, the customers are able to digitally transform their processes and operations since the functionalities they need are given through different applications built on top of the platform.

How the platform delivers value: To be able to deliver the value proposition, the platform company accesses and integrates data from different systems. The platform company has no ambition to own or exploit raw data; it only aims to offer value by handling and integrating data and prepar- ing these for the customers. Thus, the platform company supports the customers' digital transformation processes while retaining ownership of algorithms and tools, functionalities, and capabilities of the platform. It also provides digital competence while the customer has and retains domain knowledge, data ownership and process ownership. In addition, the customers can provide granular access to their data for different partners, suppliers and coopetitors in order to further enhance the operation performance together.

How the platform captures value: The platform company provides the platform-as-a-service and captures value through a subscription fee.

The Closed Platform Strategy: The digital platform, in this case, was developed by a large incumbent with a long history as a central provider of services and equipment to many oil and gas companies. The incumbent has industry-specific domain knowledge while being a technology developer, building the platform and developing software and applications. The company's central role in operations involves access to large amounts of historical data.

The platform was designed to give the incumbent access to advanced data related to the use and maintenance of different machines delivered by the incumbent across a large number of customers and facilities. These data enable comparisons and an analysis of each individual machine, hence forming a basis for enhancing and optimising maintenance and operations to increase economic margins.

The data insight enables the incumbent to have a competitive edge on how to operate the facilities and enables it to take over several service areas, such as drilling services, which the oil companies used to either handle themselves or source from other suppliers. The competitive edge is predicated on access to all the data gathered across the range of customers (oil companies). While each oil company retains access to its own data, only the incumbent has access to all of it.

In this situation, the ecosystem around a customer (i.e., an oil company) is mainly made up of different units within the incumbent, addressing all information needs related to the company's assets. The platform strategy may be characterised as closed and proprietary to the incumbent (Appleyard and Chesbrough 2017), and the platform's business model may be described as follows:

How the platform creates value: The value proposition of the incumbent (platform owner) is to provide holistic and optimised operation (e.g., drilling and well construction) and maintenance services to oil companies. The digital platform enables this by providing access to real-time and historical data related to the use and maintenance of different machines delivered by the incumbent. Different in- 
ternal units within the incumbent use data from the platform to provide services that are taking over large parts of the activities that used to be conducted by the customer.

How the platform delivers value: The value proposition entails that the platform company has full data access and control over the operations and facilities. Domain knowledge and extensive access to data are exploited by the incumbent as the core resource. Third parties are involved when they have agreed to streamline their processes in accordance with those of the incumbent; they act as subcontractors who have access to the data they need to provide the facilities with activities that conform to the platform company's governance.

How the platform captures value: The incumbent and the oil company have established a new performance-based contract based on the data management possibilities from the platform. This performance-based contract replaced the earlier pay-per-service contract between the incumbent and the oil company.

\section{The Implications of Open and Closed Platform Strategies}

The B2B platforms, in our cases, used either an open (democratic) or a more closed (domination) strategy. The platform strategy and business model choices have large implications for the business models and the role of other actors in the ecosystem, risk exposure, digital transformation, knowledge involved and innovation:

Business models of ecosystem actors: An open platform strategy is associated with a 'platform as a service subscription' business model. For the ecosystem actors, this represents no radical disruption but rather an opportunity for each actor in the ecosystem to incrementally improve its activities. A closed strategy is associated with a performance-oriented business model for the platform company. This business model may represent a radical change at the ecosystem level, as it transforms the value chain and the relations within the ecosystem.

Role of ecosystem actors: An ecosystem associated with an open platform strategy is aimed to be open and governed by transparency, data sharing and mutual benefits amongst partners and coopetitors. The main value rests on sharing activity data and process data between different actors. Due to competition between certain actors, data sharing is granular. The closed platform strategy insources operations of customers and other ecosystem actors. The ecosystem revolves mainly internally in different internal units of the incumbent. The customers only get access to data which they can use to verify and control the performance results of the facility. Other third-party actors use data in accordance with how the incumbent operates.
Risk exposure: The economic and legal risks involved in the open platform strategy are shared among the ecosystem actors and involve everyone using the platform, with the exception of the platform company since they only provide the platform as a service. For the closed platform strategy, the economic risk is mainly taken by the incumbent, reducing the risk exposure for the customers and other ecosystem actors.

Digital transformation: The open platform strategy enhances data insights and analysis while being pivotal in the customer's digital transformation of operational activities and processes and their enhanced operations. The platform supports the digitalisation of the customer's processes while involving the processes of related actors in the ecosystem. The closed platform strategy does not involve digital transformation for the customer or other actors in the ecosystem. On the contrary, the digital transformation and streamlining of different processes happen within the incumbent since it is the platform owner.

Knowledge involved: The domain knowledge within the open platform strategy remains for the different customers and ecosystem actors. Furthermore, the actors involved gain digital capabilities through digital transformation. Contrarily, the closed platform strategy involves insourcing domain knowledge and operational activities at the incumbent at the expense of the customers and ecosystem actors.

Innovation: The open platform strategy enhances innovation for all the actors involved. The platform owner can introduce platform innovation or new apps on top of the platform, or they can incrementally change the platform for other industries. The customers may innovate through digital transformation across different operations and units, while other ecosystem actors can both innovate directly by using the platform and adding their applications on the open APIs or by better integrating their processes with the customer. The closed platform strategy enhances innovation only for the incumbent internally by insourcing customers' operations and reducing the number of ecosystem actors.

The implications are summarised in Tab. 1.

\section{Concluding Remarks}

The two B2B platforms described in this commentary expose two opposite strategies. The open platform strategy exposes a democratic approach providing benefits for all actors involved due to data sharing. The platform is developed in an inclusive manner; the involvement of thirdparty actors within the ecosystem is also inclusive, and the risks of the operations are spread among all the actors involved. Both transparency and inclusion form an inte- 


\begin{tabular}{|c|c|c|}
\hline Implications & Open platform strategy & Closed platform strategy \\
\hline $\begin{array}{l}\text { Business model of } \\
\text { ecosystem actors }\end{array}$ & $\begin{array}{l}\text { No radical disruption for the ecosystem } \\
\text { actors. }\end{array}$ & $\begin{array}{l}\text { Radical change at the ecosystem level. The value } \\
\text { chain and the relations within the ecosystem are } \\
\text { transformed. }\end{array}$ \\
\hline $\begin{array}{l}\text { Role of ecosystem } \\
\text { actors }\end{array}$ & $\begin{array}{l}\text { The ecosystem is open and governed by } \\
\text { transparency, data sharing and mutual benefits } \\
\text { amongst partners and coopetitors. }\end{array}$ & $\begin{array}{l}\text { The ecosystem is closed and embedded in different } \\
\text { internal units of the incumbent. The customers only } \\
\text { get access to data that they can use to verify and } \\
\text { control the performance of the services provided. }\end{array}$ \\
\hline Risk exposure & Risks are shared among the ecosystem actors. & Risks rest at the incumbent. \\
\hline $\begin{array}{l}\text { Digital } \\
\text { transformation }\end{array}$ & $\begin{array}{l}\text { The platform is central to customers' digital } \\
\text { transformation. }\end{array}$ & $\begin{array}{l}\text { The digital transformation and streamlining of } \\
\text { different processes happen within the incumbent. }\end{array}$ \\
\hline Knowledge & $\begin{array}{l}\text { The domain knowledge within the open } \\
\text { platform strategy remains for customers and } \\
\text { ecosystem actors. }\end{array}$ & Insourcing domain knowledge at the incumbent. \\
\hline Innovation & $\begin{array}{l}\text { Enhancing innovation for all the actors in the } \\
\text { ecosystem. }\end{array}$ & $\begin{array}{l}\text { Enhancing innovation internally for the incumbent by } \\
\text { insourcing customers' operations and reducing the } \\
\text { number of ecosystem actors. }\end{array}$ \\
\hline
\end{tabular}

Tab. 1: Implications of open and closed platform strategies

gral part of the platform strategy, in line with open strategy research (Whittington et al. 2011).

On the other hand, the closed platform strategy involves a domination approach, where an incumbent takes control of the data and the involved operations. The risks rest at the incumbent. The platform is closed to the customers and other ecosystem actors. The sharing of data with other actors in the ecosystem is limited to cases where other actors follow and comply with the processes and governance of the incumbent, in line with a closed strategy approach (Appleyard and Chesbrough 2017).

From a theoretical viewpoint, the open and closed B2B platform strategies identified in our cases confirm that the mechanisms underlying the growth and value creation of B2B platforms are different from those of B2C platforms. While B2C platforms often grow and capture value by increasing the customer base (Huang et al. 2017), our cases suggest that B2B platforms can either grow through a democratic strategy where all actors of the industrial ecosystem are involved or through a domination strategy where an incumbent takes control of the data and operations. The evidence from these cases also demonstrates that the two strategies are associated with different business models, as called for by Jacobides et al. (2018).

The case data also indicate that the antecedents of the two platform strategies vary. While a democratic strategy requires that several actors in the industrial ecosystem are willing to share data, for example, the domination strategy might require a large actor with a heritage in the industry that is willing to take a dominant role. Further empirical research is needed to better understand what the antecedents and implications of the two strategies are for different organisations in various B2B ecosystems. Further research is also needed to identify platform strategies in between the two outliers identified in our cases to provide a more fine-grained overview of potential strategies for B2B platform providers.

\section{A Call for Decentralized Governance of Fair Ecosystems}

\author{
By Jaap Gordijn, Fadime Kaya, and Roel Wieringa
}

\section{Introduction}

Over the past decade, we have seen the rise of many centralized ecosystems. Examples include Facebook, Amazon, Google, WhatsApp, WeChat, Uber, and many more. We call these centralized ecosystems because they are controlled (a.k.a. governed) by companies after which the entire ecosystem is named. The controlling party usually takes an intermediate position and plays the role of a trusted party. Often this leads to situations such as exceptional profit, high transaction costs for suppliers, and high switching costs so that the controlling company effectively has a monopoly, easily leading to economic disbalance in society. We refer to this phenomenon as value extraction; parties wringing out an ecosystem, rather than that everyone acting in the ecosystem is winning.

Value extraction is not in the interest of societies in general and also not beneficial for many of the parties in the centralized ecosystem. Some countries react to this trend by fining the controlling actor in the ecosystem. In contrast, we argue that societies should develop decentralized ecosystems, including a fair distribution of decision power over the affected stakeholders in the ecosystem, such that no actor can take a too powerful role. Specifically, the governance of ecosystems should be fair and decentralized. We position blockchain technology as a tool to support de- 
centralized governance but also argue that with respect to decentralized governance, most blockchain technologies are only in their preliminary phase. To be really useful, blockchain systems should support on-chain governance in such a way that it is comprehensible and transparent to all parties involved.

\section{Ecosystems and Platforms}

We define an ecosystem as a system of economic actors that depend on each other for their economic survival and well-being (Kaya et al. 2020). Any company, not-for-profit organization, or government is part of at least one ecosystem. For example, the energy ecosystem consists of generators, distribution- and transportation companies, parties providing metering services, and obviously end-users, either companies or households consuming energy. The music ecosystem comprises creative entities such as artists and text- and song writers, producers, radio- and television stations, restaurants and bars, intellectual property right societies, and people who listen to music. The above ecosystems are much more complex in reality, both in terms of participating actors as in terms of the products and services offered and requested.

A platform provides the infrastructure for an ecosystem. We view the platform as a construct that provides (reusable) products or services to ecosystems. Similarly, a platform may use products or services from other platforms. Take, for example, Android, the operating system for mobile phones. The Android platform provides services by offering an Application Programming Interface (API) to apps such as Facebook, LinkedIn, Google mail, etc. Part of the services of the Android platform is also directly available to the end-user, e.g., the included Chrome web browser. Moreover, the Android platform uses hardware platforms, such as those managed by Samsung, Sony, and many Chinese hardware manufacturers. Note that a platform itself is also an ecosystem. In the case of Android, it is very well possible to state the participating actors and the products and services they offer to each other.

\section{The Trend of Centralization}

Many companies do, or have the ambition to, run a platform and effectively become the middleman between parties. Over the past decade, we have seen a trend towards centralized platforms, which we define as platforms in which a single actor plays a controlling role and, typically, takes a significant amount of the total profit. There are many such centralized platforms, including Facebook, LinkedIn, Google, Twitter, Uber, Airbnb, Netflix, Amazon, and many more. We have analyzed a number of these centralized platforms, and a pattern can be observed. Most centralized platforms have the ambition to have a global market, and in fact, want to have a monopoly in that mar- ket. To achieve this goal, usually exceptional high investments are needed to take most of the market share. Also, sometimes products or services are offered for cost price or even lower, to attract customers and to destroy the competition. In other cases, suppliers of the platform are encouraged to contribute in return for high fees. After a number of years, when the competition is reduced, customer prices can be increased, and supplier fees may be reduced. Once this happens, the platform owner makes a substantial profit (margins $>30 \%$ are not unusual), and often the profit is not proportional with the value created. We call such parties value extractors, indicating that the earnings are exceptionally high in relation to the contribution to the ecosystem.

Value extraction is beneficial for the platform owner, but not always for the customer (he pays a too high price) and suppliers (they are forced to offer their products and service too cheap). It is also doubtful if the monopolistic strategy is beneficial for society as a whole. It may reduce choice for customers significantly, not only in terms of possible sellers but also in terms of alternative products and services available. In other cases, there is tax avoidance, while the company at hand still benefits from the infrastructure in a country. The centralized platforms also control the terms and conditions of their platform. This may lead to undesired situations, too, for example, in the case of a content-driven platform where censorship lies in wait. All in all, centralized platforms may lead to excesses and ultimately 'digital colonialism'.

\section{What to do About It?}

What to do about centralized platforms? The European Union (EU), for example, fines large US tech firms. The effects are, however, doubtful. Although the fines, in absolute terms, are serious, they seem not to harm the fined party that much. We argue that more positive action is needed, namely the stimulation of so-called fair decentralized ecosystems and platforms. With respect to ecosystems, and thus platforms, we make the distinction between the operation of the ecosystem and its governance. We define governance in an ecosystem as the set of rules a system has to obey and which are set by another system (Kaya et al. 2020). This needs some clarification. In centralized ecosystems and platforms, there is only one actor in the governing role, namely the platform owner. Perhaps the shareholders govern the platform owner in turn, but this is usually driven by shareholder value, not always in the interest of society, and also a matter of meta-governance. As there is only one governing actor, decision making, e.g., about new rules, is easy. A single enterprise such as Amazon or Google simply can employ hierarchical decision making; In the end, the CEO decides. In a decentralized setup, there is more than one party in both the operating ecosystem (producing the actual economic value), as well as in 
the governing ecosystem. The latter ecosystem defines rules (and perhaps even legislation) the operating ecosystem has to comply with and monitors compliance. Monitoring may lead to revised rules. If needed, incentives in terms of rewards or penalties can be given to stimulate desired behaviour. In terms of decision making, a decentralized ecosystem needs to employ some decision model that takes into account the different interests of the participants. There are many of these decision models possible, including voting with many variations (majority vote, delegated vote, rotating vote, etc.). Equally important, however, is the decentralized process that leads to a decision, e.g., orientation on the subject matter, taking a position, perhaps after consulting others. This usually takes the form of a negotiation process.

We argue that fair ecosystems require fair decentralized governance. In other words, if the governance structure is fair and decentralized, the operating ecosystem will be fair too. Inspired on Graham et al. (2003) and Sheng (2009), decentralized governance is fair if it satisfies a number of requirements. First, all affected participants should be actively involved in the decision process. This is not always easy, most often due to a lack of knowledge, interest, knowledge, or time. Consequently, in many democracies, there are elected parties that represent a large group of stakeholders. Second, all participants should be treated equally. This should be safeguarded by a balanced set of rules. Third, the information needed to make a decision should be freely, timely, and transparently available to parties in a digestible form. Fourth, the governance process should be timely, meaning that decisions are made within an acceptable timeframe. Fifth, the decision model used should strive for consensus. Sixth, all participants should be accountable for their behaviour, e.g., meaning that there is a transparent trace of their actions.

If fair decentralized governance should serve as an alternative for the centralized governance by many US tech firms, governance should not only be defined in terms of parties, rules (and legislation), incentives, decision-making procedures, etc. but should also be supported by technology, to cope with the fast-evolving Internet enabling centralized competitors. Blockchain technology is a distributed technology solution that may support decentralized ecosystems. Many blockchain projects have been developed, but only a few are successful (Trujillo et al. 2017). We claim that the reason for a high failure rate of blockchain projects is that most of them do not remove, or at least reduce, the role of the middlemen. As a distributed technology, blockchain is very expensive, both in terms of design and operation, and hence can only be justified by very large benefits. Also, there might be a shift of benefits from one actor to the other, e.g., by a disruption in the ecosystem. One such disruption can be the reduction or removal of a centralized platform actor, e.g., a transition of
eBay to a fully decentralized marketplace (OpenBazaar 2019) where matching and price formation is completely decentralized; hence no single enterprise can take the powerful position of deciding upon matches and prices.

In the above example, the operations of an ecosystem are decentralized to avoid that one actor can dominate the ecosystem. However, the rules, e.g., with respect to decentralized matching and price formation, need to be set by someone too, and this is how real fairness happens. We consider rule-setting and checking for compliance as an important task of the decentralized governance ecosystem. Therefore, we state that if blockchain technology is used to support a fair decentralized ecosystem, preferably, that same technology should also support fair decentralized governance. We have done an analysis of three decentralized blockchain platforms (Jairam et al. 2021), namely Bitcoin, Ethereum, and Tezos, with respect to decentralized fair governance. The governance processes of the Bitcoin ecosystem, and to a larger extent the Ethereum ecosystem, involves only a small group of participants, as compared to the number of users in the blockchain technology itself. This is a sign that, although the ecosystem is from an operational perspective is fully decentralized, it is not from a governance point of view. Also, the process to arrive at a decision is, at best informal. Tezos (Allombert et al. 2019) is a blockchain platform with on-chain governance, meaning that the governance processes are supported by blockchain mechanisms such as transactions and smart contracts. Such contracts provide a more formal foundation for the expression of governance structures, but they are still in an initial phase. Another trend is socalled Decentralized Autonomous Organizations (DOAs). The Effect Network ${ }^{4}$ is a DOA that focuses on offering a scalable workforce (e.g., mechanical Turk services) by using the EOS blockchain technology. These DOAs have implemented decentralized governance as a series of smart contracts on the blockchain, including the required decision-making logic.

Although we think that on-chain governance is the way to proceed, the challenge is to develop governance constructs such that every interested stakeholder can participate and thus can understand. Currently, governance of blockchain-enabled ecosystems requires too much (technical) knowledge of the blockchain programming languages at hand. To solve this, we develop the DECENT (decentralized) governance ontology. It provides a series of intuitive concepts to describe various aspects of decentralized governance. The ontology can be extended with high-level modelling languages such as the Business Process Modelling Notation (BPMN) and $e^{3}$ value for modelling the economic value aspects of the ecosystem at hand. The ambition is that such semi-formal models can be used to gener-

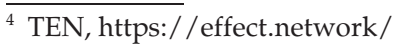


ate smart contracts for on-chain blockchain platforms such as Tezos or DOAs. By offering graphical conceptual modelling techniques to express governance solutions, we anticipate bridging the gap between technology-oriented smart contracts on the one hand and business requirements on the other hand.

\section{Conclusion}

Many companies strive for a centrally led ecosystem. For the company at hand, this might be beneficial, but as it can easily result in value extraction, it is not in the interest of society. Rather than fining the well-known centralized platforms, a better approach is to develop viable and moreover fair alternatives, organized as decentralized ecosystems, where decision power is well balanced. Blockchain technology can play an enabling role here, but there is work to do. First, blockchain systems should provide rich support for decentralized on-chain governance. Second, the expression of governance structures should be closer to the end-users, rather than requiring in-depth knowledge about distributed systems programming. High-level graphical modelling languages can help here, provided that automated translation of models in these languages to smart contracts is supported.

\section{References}

Adamczyk S, Bullinger AC and Moeslein KM (2011) Commenting for new ideas: insights from an open innovation platform. International Journal of Technology Intelligence and Planning 7(3): 232. DOI: 10.1504/IJTIP.2011.044612.

Adner R (2006) Match your innovation strategy to your innovation ecosystem. Harvard Business Review 84(4).

Adner R (2017) Ecosystem as Structure: An Actionable Construct for Strategy. Journal of Management 43(1): 39-58. DOI: $10.1177 / 0149206316678451$.

Adner R and Kapoor R (2010) Value creation in innovation ecosystems: how the structure of technological interdependence affects firm performance in new technology generations. Strategic Management Journal 31(3): 306-333. DOI: 10.1002 /smj.821.

Allmendinger G and Lombreglia R (2005) Four strategies for the age of smart services. Harvard Business Review 83(10): $131-145$.

Allombert V, Mathias B. and Tesson J (2019) Introduction to the Tezos blockchain. In: Proceedings of the International Conference on High Performance Computing \& Simulation (HPCS), 2019.

Anke J, Ebel M, Poeppelbuss J, et al. (2020) How to tame the Tiger - Exploring the Means, Ends, and Challenges in Smart Service Systems Engineering. In: Proceedings of the 28th European Conference on Information Systems (ECIS), 2020.

Anke J, Poeppelbuss J and Alt R (2020) It Takes More than Two to Tango: Identifying Roles and Patterns in Multi-Actor Smart Service Innovation. Schmalenbach Business Review 72(4): 599-634. DOI: 10.1007/s41464-020-00101-2.

Appleyard MM and Chesbrough HW (2017) The Dynamics of Open Strategy: From Adoption to Reversion. Long Range Planning 50(3): 310-321. DOI: 10.1016/j.lrp.2016.07.004.
Arreola González A, Pfaff M and Krcmar H (2019) Value Modeling for Ecosystem Analysis. Computers. DOI: 10.3390/ computers 8030068 .

Autio E and Thomas LDW (2020) Value co-creation in ecosystems: insights and research promise from three disciplinary perspectives. In: Nambisan S, Lyytinen K, and Yoo Y (eds) Handbook of Digital Innovation. Cheltenham, UK: Edward Elgar Publishing, pp. 107-132. DOI: 10.4337/9781788119986. 00017.

Baden-Fuller C and Haefliger S (2013) Business Models and Technological Innovation. Long Range Planning 46(6): 419426. DOI: $10.1016 /$ j.lrp.2013.08.023.

Baldwin CY and Woodard CJ (2008) The Architecture of Platforms: A Unified View. SSRN Electronic Journal. DOI: 10.2139/ssrn.1265155.

Bankvall L, Dubois A and Lind F (2017) Conceptualizing business models in industrial networks. Industrial Marketing Management 60: 196-203. DOI: 10.1016/j.indmarman.2016. 04.006 .

Barbosa F, Bresciani G, Graham P, et al. (2020) Oil and gas after COVID-19: The day of reckoning or a new age of opportunity. Available at: https://www.mckinsey.com/industrie s/oil-and-gas/our-insights/global-energy-perspective-2021 (accessed 11 June 2021).

Barrett M, Davidson E, Prabhu J, et al. (2015) Service innovation in the digital age: Key contributions and future directions. MIS Quarterly 39(1): 135-154. DOI: 10.25300/MISQ/ 2015/39:1.03.

Becker J, Beverungen D, Knackstedt R, et al. (2013) Bridging the Gap Between Manufacturing and Service Through ITBased Boundary Objects. IEEE Transactions on Engineering Management 60(3): 468-482. DOI: 10.1109/TEM.2012.2214770.

Beverungen D, Lüttenberg H and Wolf V (2018) Recombinant service systems engineering. Business $\mathcal{E}$ Information Systems Engineering 60(5): 377-391. DOI: 10.1007/s12599-0180526-4.

Beverungen D, Müller O, Matzner M, et al. (2019) Conceptualizing smart service systems. Electronic Markets 29(1): 7-18. DOI: $10.1007 / \mathrm{s} 12525-017-0270-5$.

Beverungen D, Kundisch D and Wünderlich N (2020) Transforming into a platform provider: strategic options for industrial smart service providers. Journal of Service Management 32(4): 507-532. DOI: 10.1108/JOSM-03-2020-0066.

Biemans W and Griffin A (2018) Innovation practices of B2B manufacturers and service providers: Are they really different? Industrial Marketing Management 75: 112-124. DOI: 10.1016/j.indmarman.2018.04.008.

Brennan R (2018) Business-to-Business Marketing. In: Alhajj R and Rokne J (eds) Encyclopedia of Social Network Analysis and Mining. New York, NY: Springer New York, pp. 172-176. DOI: 10.1007/978-1-4939-7131-2_270.

Casadesus-Masanell R and Ricart JE (2010) From Strategy to Business Models and onto Tactics. Long Range Planning 43(2-3): 195-215. DOI: 10.1016/j.lrp.2010.01.004.

Coreynen W, Matthyssens P and Van Bockhaven W (2017) Boosting servitization through digitization: Pathways and dynamic resource configurations for manufacturers. Industrial Marketing Management 60: 42-53. DOI: 10.1016/j.indmarman.2016.04.012.

Dayan M and Ndubisi NO (2020) B2B service innovation and global industrial service management. Industrial Marketing 
Management 89: 140-142. DOI: 10.1016/j.indmarman.2019. 08.006 .

de Reuver M, Sørensen C and Basole RC (2018) The Digital Platform: A Research Agenda. Journal of Information Technology 33(2): 124-135. DOI: 10.1057/s41265-016-0033-3.

Djellal F and Gallouj F (2018) Fifteen challenges for Service Innovation Studies. In: Djellal F and Gallouj F (eds) A Research Agenda for Service Innovation. Edward Elgar Publishing, pp. 1-26. DOI: $10.4337 / 9781786433459.00005$.

Edvardsson B, Tronvoll B and Witell L (2018) An ecosystem perspective on service innovation. In: Djellal $\mathrm{F}$ and Gallouj $\mathrm{F}$ (eds) A Research Agenda for Service Innovation. Edward Elgar Publishing, pp. 85-102. DOI: 10.4337/9781786433459.00009.

Eisenmann T, Parker G and van Alstyne M (2006) Strategies for two-sided markets. Harvard Business Review 84(10): 92101.

Ekman P, Raggio RD and Thompson SM (2016) Service network value co-creation: Defining the roles of the generic actor. Industrial Marketing Management 56: 51-62. DOI: 10.1016/j.indmarman.2016.03.002

Fielt E (2013) Conceptualising Business Models: Definitions, Frameworks and Classifications. Journal of Business Models 1(1): 85-105. DOI: 10.5278/ojs.jbm.v1i1.706.

Fielt E, Janssen W, Faber E, et al. (2008) Design Trade-offs for Electronic Intermediaries. Electronic Markets 18(4): 362-374. DOI: $10.1080 / 10196780802420760$.

Fiol CM and O'Connor EJ (2003) Waking up! Mindfulness in the Face of Bandwagons. The Academy of Management Review 28(1): 54-70. DOI: 10.2307/30040689.

Gawer A (2014) Bridging differing perspectives on technological platforms: Toward an integrative framework. Research Policy 43(7): 1239-1249. DOI: 10.1016/j.respol.2014.03.006.

Gawer A (2020) Introduction to Part III. In: Nambisan S, Lyytinen $\mathrm{K}$, and Yoo Y (eds) Handbook of Digital Innovation. Cheltenham, UK: Edward Elgar Publishing, pp. 98-106. DOI: 10.4337/9781788119986.00016.

Gawer A and Cusumano MA (2014) Industry platforms and ecosystem innovation. Journal of Product Innovation Management 31(3): 417-433. DOI: 10.1111/jpim.12105.

Goodwin T (2015) The Battle Is For The Customer Interface. Available at: https://techcrunch.com/2015/03/03/in-theage-of-disintermediation-the-battle-is-all-for-the-customerinterface/?guccounter $=1$ (accessed 11 June 2021).

Gordijn J and Akkermans H (2001) Designing and evaluating e-business models. IEEE Intelligent Systems 16(4): 11-17. DOI: $10.1109 / 5254.941353$.

Graham J, Amos B and Plumptre T (2003) Principles for Good Governance in the 21st Century. Policy Brief 15.

Hagiu A and Rothmann S (2016) Network Effects Aren't Enough. Harvard Business Review 94(4): 64-71.

Hanelt A, Nischak F, Markus N, et al. (2020) Building platform ecosystems for IoT - Exploring the impact on industrial-age firms. In: Proceedings of the 28th European Conference on Information Systems (ECIS), 2020.

Hein A, Schreieck M, Riasanow T, et al. (2020) Digital platform ecosystems. Electronic Markets 30(1): 87-98. DOI: $10.1007 /$ s12525-019-00377-4.

Helfat CE and Raubitschek RS (2018) Dynamic and integrative capabilities for profiting from innovation in digital platform-based ecosystems. Research Policy 47(8): 13911399. DOI: 10.1016/j.respol.2018.01.019.
Hevner A and Malgonde O (2019) Effectual application development on digital platforms. Electronic Markets 29(3): 407421. DOI: $10.1007 /$ s12525-019-00334-1.

Hofman E and Meijerink J (2015) Platform thinking for services: the case of human resources. The Service Industries Journal 35(3): 115-132. DOI: 10.1080/02642069.2014.989999.

Huang J, Henfridsson O, Liu MJ, et al. (2017) Growing on Steroids: Rapidly Scaling the User Base of Digital Ventures Through Digital Innovation. MIS Quarterly 41(1): 301-314. DOI: 10.25300/MISQ/2017/41.1.16.

Huber RXR, Püschel LC and Röglinger M (2019) Capturing smart service systems: Development of a domain-specific modelling language. Information Systems Journal 29(6): 12071255. DOI: $10.1111 /$ isj.12269.

Humbeck P, Jaeckle JP, Duwe J, et al. (2020) The Business Ecosystem Management Canvas. In: IEEE International Conference on Industrial Engineering and Engineering Management (IEEM), 2020, pp. 249-254. DOI: 10.1109/IEEM45057.2020.9309731.

Hurtta, Kim and Elie-Dit-Cosaque C (2017) Digital innovation in public service ecosystem: Enacting the generative affordance. In: Proceedings of the 25th European Conference on Information Systems (ECIS), 2017.

Hydle K, Hanseth O, Aanestad M, et al. (2021) Digital Transformation through Collaborative Platformization: A Study of Incumbent-Entrepreneur Relations. In: Proceedings of the Hawaii International Conference on System Sciences (HICSS), 2021. DOI: 10.24251/HICSS. 2021.707.

Jacobides MG, Cennamo C and Gawer A (2018) Towards a theory of ecosystems. Strategic Management Journal 39(8): 2255-2276. DOI: 10.1002/smj.2904.

Jacobides MG, Sundararajan A and van Alstyne M (2019) Platforms and Ecosystems: Enabling the Digital Economy. Cologny/ Geneva, Switzerland: World Economic Forum.

Jairam S, Gordijn J, da Torres IS, et al. (2021) A Decentralized Fair Governance Model for Permissionless Blockchain Systems. In: CEUR Proceeding of the Workshop of Value Modelling and Business Ontologies, CEUR 2835, 2021. Available at: http:/ / ceur-ws.org/Vol-2835/paper3.pdf.

John T, Kundisch D and Szopinski D (2017) Visual Languages for Modeling Business Models: A Critical Review and Future Research Directions. Proceedings of the 38th International Conference on Information Systems (ICIS).

Kaya F, Gordijn J, Wieringa R, et al. (2020) Exploring governance in a decentralized energy trading eco-system. In: Proceedings of the33RD BLED e-conference: Enabling Technology for a Sustainable Society, 2020.

Keijl S, Gilsing VA, Knoben J, et al. (2016) The two faces of inventions: The relationship between recombination and impact in pharmaceutical biotechnology. Research Policy 45(5): 1061-1074. DOI: 10.1016/j.respol.2016.02.008.

Kohtamäki M, Parida V, Oghazi P, et al. (2019) Digital servitization business models in ecosystems: A theory of the firm. Journal of Business Research 104: 380-392. DOI: 10.1016/ j.jbusres.2019.06.027.

Leijon E, Svenheden J and Svahn F (2017) Platform Thinking in Incumbent Firms: From Concept to Capability. Proceedings of the 50th Hawaii International Conference on System Sciences (HICSS): 4766-4775.

Lusch RF and Nambisan S (2015) Service innovation: A service-dominant logic perspective. MIS Quarterly 39(1): 155175. DOI: 10.25300/MISQ/2015/39.1.07. 
Lüttenberg H (2020) PS3 - A Domain-Specific Modeling Language for Platform-Based Smart Service Systems. In: Hofmann S, Müller O, and Rossi M (eds) Lecture Notes in Computer Science. 12388th ed. Cham: Springer, pp. 438-450. DOI: 10.1007/978-3-030-64823-7_42.

Mason K and Spring M (2011) The sites and practices of business models. Industrial Marketing Management 40(6): 10321041. DOI: 10.1016/j.indmarman.2011.06.032.

Mini T and Widjaja T (2019) Tensions in Digital Platform Business Models: A Literature Review. Proceedings of the 40th International Conference on Information Systems (ICIS).

Mody M, Wirtz J, Fung So KK, et al. (2020) Two-directional convergence of platform and pipeline business models. Journal of Service Management 31(4): 693-721. DOI: 10.1108/ JOSM-11-2019-0351.

Nambisan S (2013) Information Technology and Product/Service Innovation: A Brief Assessment and Some Suggestions for Future Research. Journal of the Association for Information Systems 14(4): 215-226. DOI: 10.17705/1jais.00327.

National Science Foundation (2014) Partnerships for Innovation: Building Innovation Capacity (PFI:BIC). Available at: https://www.nsf.gov/pubs/2014/nsf14610/nsf14610.pdf (accessed 11 June 2021).

OpenBazaar (2019) Buy and Sell Freely. Available at: https:/ / openbazaar.org/ (accessed 15 October 2019).

Osterwalder A and Pigneur Y (2010) Business Model Generation: A Handbook for Visionaries, Game Changers, and Challengers. 1st ed. Haboken, New Jersey, USA: John Wiley \& Sons, Inc.

Ostrom AL, Parasuraman A, Bowen DE, et al. (2015) Service Research Priorities in a Rapidly Changing Context. Journal of Service Research 18(2): 127-159. DOI: 10.1177/10946705155 76315.

Paiola M and Gebauer H (2020) Internet of things technologies, digital servitization and business model innovation in BtoB manufacturing firms. Industrial Marketing Management 89: 245-264. DOI: 10.1016/j.indmarman.2020.03.009.

Palo T and Tähtinen J (2013) Networked business model development for emerging technology-based services. Industrial Marketing Management 42(5): 773-782. DOI: 10.1016/ j.indmarman.2013.05.015.

Parida V, Burström T, Visnjic I, et al. (2019) Orchestrating industrial ecosystem in circular economy: A two-stage transformation model for large manufacturing companies. Journal of Business Research 101: 715-725. DOI: 10.1016/j.jbusres.2019.01.006.

Parker G, van Alstyne M and Jiang X (2016) Platform Ecosystems: How Developers Invert the Firm. SSRN Electronic Journal 41(1): 255-266. DOI: 10.2139/ssrn.2861574.

Parker G, van Alstyne M and Choudary S (2016) Platform Revolution: How Networked Markets Are Transforming the Economy and How to Make Them Work for You. New York, NY, USA: W. W. Norton \& Company.

Pauli T, Marx E, Dunzer S, et al. (2020) Modeling Platform Ecosystems. ER Forum, Demo and Posters: 17-30. Available at: http:/ / ceur-ws.org/Vol-2716/paper2.pdf.

Pauli T, Fielt E and Matzner M (2021) Digital Industrial Platforms. Business E Information Systems Engineering 63(2): 181190. DOI: $10.1007 /$ s12599-020-00681-w.

Penttinen E, Halme M, Lyytinen K, et al. (2018) What Influences Choice of Business-to-Business Connectivity Plat- forms? International Journal of Electronic Commerce 22(4): 479-509. DOI: 10.1080/10864415.2018.1485083.

Petrik D and Herzwurm G (2020) Boundary resources for IIoT platforms - a complementor satisfaction study. In: Proceedings of the 41st International Conference on Information Systems (ICIS), 2020.

Poniatowski M, Lüttenberg H, Beverungen D, et al. (2021) Three layers of abstraction: a conceptual framework for theorizing digital multi-sided platforms. Information Systems and e-Business Management: 1-27. DOI: 10.1007/s10257-02100513-8.

Porter ME and Heppelmann JE (2014) How smart, connected products are transforming competition. Harvard Business Review 92(11): 64-88.

Powell WW (1990) Neither market nor hierarchy: Network forms of organization. In: Staw B and Cummings LL (eds) Research in Organizational Behavior. Greenwich: JAI Press, pp. 295-336.

Rayna T and Striukova L (2014) The Impact of 3D Printing Technologies on Business Model Innovation. In: Proceedings of the Second International Conference on Digital Enterprise Design \& Management, 2014, pp. 119-132. DOI: 10.1007/978-3319-04313-5_11.

Rochet JC and Tirole J (2003) Platform competition in two-sided markets. Journal of the European Economic Association 1(4): 990-1029. DOI: 10.1162/154247603322493212.

Sawhney MS (1998) Leveraged High-Variety Strategies: From Portfolio Thinking to Platform Thinking. Journal of the Academy of Marketing Science 26(1): 54-61. DOI: 10.1177/ 0092070398261006.

Schilling MA (2000) Toward a General Modular Systems Theory and Its Application to Interfirm Product Modularity. Academy of Management Review 25(2): 312-334. DOI: 10.5465/amr.2000.3312918.

Schreieck M, Wiesche M and Krcmar H (2016) Design and governance of platform ecosystems - Key concepts and issues for future research. In: Proceedings of the 24th European Conference on Information Systems (ECIS), 2016.

Schumpeter JA (1934) The Theory of Economic Development: An Inquiry into Profits, Capital, Credit, Interest, and the Business Cycle. Cambridge, Mass.: Harvard University Press.

Schymanietz M and Jonas JM (2020) The Roles of Individual Actors in Data-Driven Service Innovation - A Dynamic Capabilities Perspective to Explore its Microfoundations. In: Proceedings of the Hawaii International Conference on System Sciences (HICSS), 2020, pp. 1135-1144. DOI: 10.24251/ HICSS. 2020.142.

Sheng YK (2009) What is good governance. United Nations Economic and Social Commission for Asia and the Pacific.

Smith WK, Binns A and Tushman ML (2010) Complex Business Models: Managing Strategic Paradoxes Simultaneously. Long Range Planning 43(2-3): 448-461. DOI: 10.1016/ j.lrp.2009.12.003.

Swanson and Ramiller (2004) Innovating Mindfully with Information Technology. MIS Quarterly 28(4): 553. DOI: $10.2307 / 25148655$.

Talmar M, Walrave B, Podoynitsyna KS, et al. (2020) Mapping, analyzing and designing innovation ecosystems: The Ecosystem Pie Model. Long Range Planning 53(4). DOI: https://doi.org/10.1016/j.lrp.2018.09.002.

Täuscher K and Abdelkafi N (2017) Visual tools for business 
model innovation: Recommendations from a cognitive perspective. Creativity and Innovation Management 26(2). John Wiley \& Sons, Ltd: 160-174. DOI: https://doi.org/10.1111/ caim.12208.

Thomas LDW, Autio E and Gann DM (2014) Architectural Leverage: Putting Platforms in Context. Academy of Management Perspectives 28(2): 198-219. DOI: 10.5465/amp.2011.0105.

Tongur S and Engwall M (2014) The business model dilemma of technology shifts. Technovation 34(9): 525-535. DOI: 10.1016/j.technovation.2014.02.006.

Trabucchi D and Buganza T (2021) Landlords with no lands: a systematic literature review on hybrid multi-sided platforms and platform thinking. European Journal of Innovation Management ahead-of-p(ahead-of-print). DOI: 10.1108/ EJIM-11-2020-0467.

Trujillo JL, Fromhart S and Srinivas V (2017) Evolution of blockchain technology - Insights from the GitHub platform. Available at: https://www2.deloitte.com/us/en/insights / industry / financial-services/evolution-of-blockchain-githu b-platform.html (accessed 14 December 2018).

Turber S and Smiela C (2014) A business model type for the internet of things. In: Proceedings of the 22nd European Conference on Information Systems (ECIS), 2014. Available at: http://aisel.aisnet.org/ecis2014/.

Tushman ML and O'Reilly III CA (1996) Ambidextrous Organizations: Managing Evolutionary and Revolutionary Change. California Management Review 38(4): 8-29. DOI: $10.2307 / 41165852$.

van Alstyne M, Parker G and Choudary S (2016) Pipelines, Platforms, and the New Rules of Strategy. Harvard Business Review 94(4): 54-62.

van Weele AJ (2005) Purchasing \& Supply Chain Management: Analysis, Strategy, Planning and Practice. 4th ed. London, UK: Thomson Learning.

Vorbohle C and Gottschalk S (2021) Towards Visualizing and Simulating Business Models in Dynamic Platform Ecosystems. In: Proceedings of the 29th European Conference on Information Systems (ECIS), 2021.

Wallbach S, Coleman K, Elbert R, et al. (2019) Multi-sided platform diffusion in competitive B2B networks: inhibiting factors and their impact on network effects. Electronic Markets 29(4): 693-710. DOI: $10.1007 /$ s12525-019-00382-7.

Waltermann HML and Hess T (2020) Competitive Recombination of Digital Technologies in the TV-Media Industry. In:
Proceedings of the 26th Americas Conference on Information Systems (AMCIS), 2020.

Weiller C and Neely A (2013) Business Model Design in an Ecosystem Context.

Weking J, Stöcker M, Kowalkiewicz M, et al. (2020) Leveraging industry 4.0 - A business model pattern framework. International Journal of Production Economics 225: 107588. DOI: 10.1016/j.ijpe.2019.107588.

Westerlund M, Leminen S and Rajahonka M (2014) Designing Business Models for the Internet of Things. Technology Innovation Management Review 4(7): 5-14. DOI: 10.22215/timreview/807.

Wheelwright SC and Clark KB (1992) Creating project plans to focus product development. Harvard Business Review 70(2): $70-82$.

Whittington R, Cailluet L and Yakis-Douglas B (2011) Opening Strategy: Evolution of a Precarious Profession. British Journal of Management 22(3): 531-544. DOI: 10.1111/j.14678551.2011.00762.x.

Yoo Y, Henfridsson O and Lyytinen K (2010) Research Commentary - The New Organizing Logic of Digital Innovation: An Agenda for Information Systems Research. Information Systems Research 21(4): 724-735. DOI: 10.1287/isre.1100. 0322.

Yoo Y, Boland RJ, Lyytinen K, et al. (2012) Organizing for Innovation in the Digitized World. Organization Science 23(5): 1398-1408. DOI: 10.1287 /orsc.1120.0771.

Zhao Y, von Delft S, Morgan-Thomas A, et al. (2020) The evolution of platform business models: Exploring competitive battles in the world of platforms. Long Range Planning 53(4): 101892. DOI: 10.1016/j.lrp.2019.101892.

Zott C and Amit R (2010) Business model design: An activity system perspective. Long Range Planning 43(2-3): 216-226. DOI: $10.1016 /$ j.lrp.2009.07.004.

Zott C, Amit R and Massa L (2011) The business model: Recent developments and future research. Journal of Management 37(4): 1019-1042. DOI: 10.1177/0149206311406265.

\section{Keywords}

Digital Platforms, Business Models, Ecosystems, Smart Services, Business-to-Business 